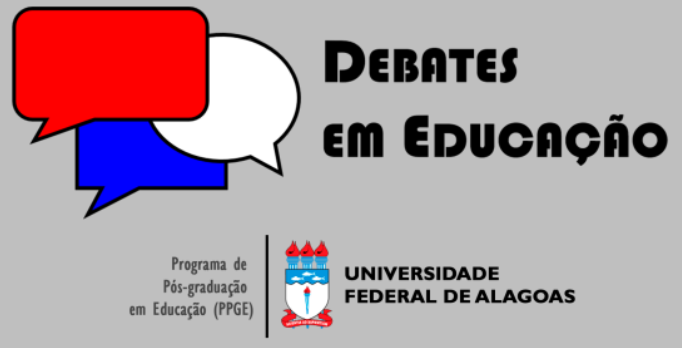

ISSN Eletrônico 2175-6600

Vol. I | | No. 23 | Jan./Abr. | 2019

\section{Amurabi Oliveira}

9 iD

Universidade Federal de Santa Catarina (UFSC) amurabi1986@gmail.com

\section{O ENSINO DE ANTROPOLOGIA EM DEBATE: ENTREVISTA COM CERES KARAM BRUM}

\section{RESUMO}

Ceres Karam Brum possui graduação em ciências jurídicas e sociais e em história, mestrado em educação e em integração latino-americana pela Universidade Federal de Santa Maria (UFSM), doutorado em antropologia pela Universidade Federal do Rio Grande do Sul (UFRGS). Atualmente é professora do departamento de ciências sociais da Universidade Federal de Santa Maria (UFSM), atuante em seu programa de pós-graduação em ciências sociais. Realizou estudos pós-doutorais na Pontifícia Universidade Católica do Rio Grande do Sul, na Escola Normal Superior de Paris e na Universidade de Lisboa.

Palavras-chave: Antropologia da Educação. História. Pesquisa. Antropologia Urbana.

\section{THE TEACHING OF ANTHROPOLOGY IN DEBATE: INTERVIEW WITH CERES KARAM} BRUM

\begin{abstract}
Ceres Karam Brum has a degree in Juridical and Social Sciences and History, a master's degree in Education and Latin American Integration from the Federal University of Santa Maria (UFSM), a PhD in Anthropology from the Federal University of Rio Grande do Sul (UFRGS). She is currently a professor in the Department of Social Sciences at the Federal University of Santa Maria (UFSM), working in the PhD Program in Social Sciences. She completed postdoctoral studies at the Pontifical Catholic University of Rio Grande do Sul and at the Escola Normal Superior of Paris and at the University of Lisbon. Professor Ceres Brum has worked in the field of Anthropology of Education and Urban Anthropology mainly.
\end{abstract}

Keywords: Anthropology of Education. History. Research. Urban Anthropology.

Submetido em: 26/09/2018

Aceito em: 30/01/2019

Ahead of print em: 04/03/2019

Publicado em: 25/04/2019

do http://dx.doi.org/10.28998/2 I 75-6600.2019v I In23p484-497 
A professora Ceres Brum tem atuado no campo da antropologia da educação e da antropologia urbana principalmente, tendo publicado inúmeros artigos e capítulos de livros relacionados a essa temática, destacando-se nos últimos anos a publicação do livro Maison du Brésil: um território brasileiro em Paris (20।4) e da coletânea A casa do Brasil de Lisboa: um projeto vitorioso (2017). Atualmente está à frente da comissão de educação, ciência e tecnologia da Associação Brasileira de Antropologia (ABA), na qual tem desenvolvido um intenso trabalho que envolve a discussão sobre o ensino de antropologia/ciências sociais no Brasil. Essa entrevista é oriunda nos inúmeros encontros que tivemos em eventos acadêmicos, tais como Reunião de Antropologia do Mercosul, Reunião Brasileira de Antropologia, Encontro Nacional da Associação Brasileira de Pesquisa e Pós-Graduação em Ciências Sociais etc., tendo sido realizada por escrito.

\section{PRIMEIRAMENTE gOSTARIA QUE VOCÊ FALASSE SOBRE SEU PROCESSO DE FORMAÇÃO NO CAMPO DAS CIÊNCIAS SOCIAIS, E DE COMO FOI SEU ENCONTRO COM A ANTROPOLOGIA.}

Amurabi, gostaria de agradecer o convite para esta entrevista. Sinto-me honrada e feliz por poder rememorar e partilhar minha trajetória com os leitores da Revista Debates em Educação (UFAL) e seus editores a quem igualmente agradeço esta oportunidade de interlocução.

Desejo começar mencionando que este rememorar corresponde à decapagem das camadas sobrepostas pelo tempo, visto do meu momento presente, como docente na Universidade Federal de Santa Maria, me parece um exercício salutar. $\bigcirc$ narrar confere esta oportunidade de descobrir uma pluralidade de sentidos a opções e escolhas que muitas vezes fazemos no curso de nossas vidas, de uma forma não muito planejada. Vamos experienciando, seguindo linhas que imaginamos traçar sem uma consciência clara do seu desenho final. Meus contatos iniciais com as Ciências Sociais se deram desta forma.

Minha primeira graduação foi em Direito cursada na UFSM que, à época, se chamava Bacharelado em Ciências Jurídicas e Sociais. Depois de concluí-la senti a necessidade de dar continuidade a minha formação e optei por cursar Licenciatura em História na mesma universidade. Foi lá que, no primeiro semestre de curso, me deparei com uma disciplina de Antropologia Cultural ministrada pela professora Neida Morales. Faço questão de mencioná-la, pois foi lá que dei os primeiros passos na Antropologia e devo a suas aulas o desejo de tornar-me antropóloga. Esse aprendizado foi importante porque percebi que na Antropologia poderia estudar o que quisesse (o que me pareceu revolucionário para as gavetas bem fechadas do armário da ciência que conhecia naquele momento). Na época eu queria trabalhar com mitos e lendas como fonte para entender a história do Rio Grande do Sul - um campo pouco popular 
entre os historiadores marxistas que ensinavam na UFSM e invisível para os juristas. Meu fascínio pela Antropologia teve a ver com uma percepção (que em parte também incluía a História cultural) como campo de conhecimento democrático que inverte as relações de poder/saber pela ampliação dos temas de pesquisa e, sobretudo, pela experiência do estranhamento. Minha opção pela Antropologia passou certamente por uma percepção epistemológica que relaciona as verdades às suas produções culturais, ultrapassando visões estereotipadas e etnocêntricas e aposta no relativismo e nas subjetividades como entendimento. Percebi, desde muito cedo, que os grupos estudados são nossos professores. É com eles que aprendemos a entender as diferenças e a respeitá-las. A delicadeza dessa tessitura do aprender "com" que se efetiva de uma forma meio mágica, seguindo os caminhos da observação foi um convite a estudar Antropologia e ter consciência de suas implicações éticas. Foi também uma forma de me situar no mundo, mas apesar de fascinante, esta foi uma decisão difícil porque entendi que a opção pela Antropologia em termos formativos implicaria meu afastamento da história e do direito. Tentei seguir esse curso pelas bordas, navegando nos mares da interdisciplinaridade durante os mestrados (em Educação e Integração Latino-Americana) até chegar ao Doutorado em Antropologia Social na Universidade Federal do Rio Grande do Sul. Lá tive excelentes professores e colegas muito generosos e, é nesse sentido, que gostaria de registrar minhas percepções sobre esse processo formativo. A importância fundamental do meu orientador, o professor Ruben George Oliven que entendeu minhas limitações e apostou na capacidade de superá-las, orientando uma etnografia que buscava, nas interpretações da história gaúcha e em suas utilizações, as matrizes da produção de identidades regionais. Minha tese sobre a produção de representações acerca do passado missioneiro - as marcas deixadas pela experiência jesuítico-guarani observada em interpretações de manifestações de grupos indígenas, pacotes turísticos, religiosidade popular, visões dos habitantes locais e grupos folclóricos me fizeram percorrer o Rio Grande do Sul, dentro e fora da região das Missões, parte da Argentina e Uruguai. Levou-me igualmente a Paris como parte do PDEE (Programa de Doutorado com Estágio no Exterior, popularmente conhecido como doutorado sanduíche) e também à Espanha onde fiz um longo trabalho de campo no Caminho de Santiago de Compostela, com o objetivo de melhor compreender o Caminho das Missões (um dos pacotes turísticos que estava pesquisando para a tese). Esta longa digressão sobre o meu encontro com a Antropologia encerra meu desejo de marcar o trabalho de campo como processo de aprendizado e, nesse contexto, a importância das pessoas que conheci e que me aceitaram como interlocutora, revelando seus universos. Para além da tese, quando passei a me reconhecer como antropóloga, gostaria de sublinhar a generosidade dos professores, colegas e estudantes com quem aprendo a cada encontro. Considero meu trabalho como docente e pesquisadora como uma experiência diária de aprendizado. 


\section{PODERIA NOS FALAR SOBRE COMO VOCÊ CHEGA À EDUCAÇÃO, OU DE MODO MAIS ESPECÍFICO, À ANTROPOLOGIA DA EDUCAÇÃO? O QUE VOCÊ TEM LECIONADO NESTE CAMPO?}

Acho que sempre o tema educação esteve mais ou menos presente na minha trajetória, mas de uma forma que extrapola a escola como temática de pesquisa. Processos de aprendizagem situada e as identidades geradas nesses contextos formativos formais e informais sempre me interessaram. Durante os mestrados, trabalhei com escritos jesuíticos e narrativas tradicionais que tratavam das relações entre índios e jesuítas nos Sete Povos das Missões. Ambas as fontes mostram a experiência de conversão e de sua manutenção como uma tarefa educacional de amplo espectro, de transformação de mundos, de culturas e de sua destruição. Assim, pensar sobre dinâmica cultural, para mim, está intimamente relacionado com entender os processos pedagógicos e educacionais envolvidos na transmissão da cultura e sua transformação. Por isso afirmo que a Antropologia sempre esteve muito próxima da educação. Processos educativos se passam em cenários culturais, como nos ensina Carlos Rodriguez Brandão - educar é criar cenários culturais e transmiti-los. E é isso que estudamos em Antropologia Social de uma maneira geral com uma série de denominações, mas o estudo da cultura e deste estar no mundo que é a educação são um todo complexo que subdividimos para melhor entender! Meu encontro com a Antropologia da educação foi uma descoberta de sujeitos e de temas que valorizam as dimensões antropológicas da educação. Em 2006, eu estava começando a trabalhar como docente no Departamento de Fundamentos da Educação da UFSM com seminários de História, Sociologia e Filosofia da Educação (a Psicologia era trabalhada à parte) e senti falta de uma discussão que pudesse auxiliar a estranhar o discurso do fracasso da escola brasileira e de relativizar os discursos maniqueístas da impotência/ onipotência da pedagogia na produção da perfectibilidade humana a partir da educação. Comecei a buscar na Antropologia elementos para alavancar reflexões sobre vários temas que não estavam sendo tratados pelos ditos "fundamentos da educação", especialmente a invisibilidade da condição dos estudantes e seus desejos na escola. Foi nessa época que encontrei os trabalhos do antropólogo da educação Christoph Wulf. Junto com alguns estudantes da Pedagogia e da educação especial formamos um grupo de estudo que denominamos DON. Era uma homenagem a Marcel Mauss. Um ponto de partida para pensar a educação em suas dimensões antropológicas, em que o ensinar e o aprender se constituem em relações de reciprocidade, de reconhecimento, de troca. Daí nasceu o seminário de Antropologia da Educação amparada pela Resolução do CNE/CP No I , de I 5 de maio de 2006 que ampliou a atuação do pedagogo para espaços não escolares voltados à docência, tais como em hospitais e escolas indígenas por exemplo. Essa ampliação implicou igualmente na alteração do corpus teórico, metodológico e prático dos cursos de Pedagogia, passando a 
Antropologia a fazer também parte dos já clássicos Fundamentos da Educação. Gosto de pensar o trabalho que venho desenvolvendo com a Antropologia da Educação em dois momentos: o da criação da disciplina de Antropologia da Educação, no Centro de Educação da UFSM, voltado para formação de pedagogos e educadores especiais (quiçá em seus primeiros contatos com a antropologia e a utilização do método etnográfico, que insistia muito no entendimento das matrizes conceituais do saber antropológico voltado para pensar a escola) e a Antropologia da Educação nos cursos de Bacharelado e Licenciatura em Ciências Sociais e no Programa de Pós-Graduação em Ciências Sociais, em que venho trabalhando desde 2008. Nesse segundo momento, o nome Antropologia da Educação adquire o status de um campo de atuação e formação para cientistas sociais/antropólogos, cuja educação em sentido ampliado é percebida como tema de reflexão estreitamente ligado à cultura e seus processos de transmissão. Nos seminários, revisitamos as matrizes do conhecimento antropológico e as relações recíprocas entre Antropologia e Educação, ao longo de suas histórias disciplinares, com um destaque especial à estruturação da área no Brasil e no mundo, em fricção com os estudos culturais. Dois temas importantes são o trabalho com o método etnográfico (os avanços da etnografia da educação e da escola e suas potencialidades de pesquisa e ação) e a desconstrução da educação como sinônimo de escolarização. Um largo investimento nas discussões sobre aprendizagem, cultura e educação vem sendo trabalhado na disciplina inspirado nos estudos de Jean Lave e Tim Ingold, seguido de um conjunto de etnografias, que nos conduzem às discussões sobre antropologia da criança e da juventude, ritos escolares, etnicidade e educação com destaque às quotas raciais e sociais na universidade e à educação indígena, estigma, inclusão e aprendizagem, religião, drogas, violência, sexualidade, ensino de sociologia no ensino médio, casas de estudantes e a educação em espaços não escolares, tais como pesca, candomblé, tradicionalismo gaúcho, etc. Nossos seminários de Antropologia da Educação têm uma flexibilidade relativa ao interesse dos estudantes pelas temáticas que desejam discutir através de etnografias previamente selecionadas e se comunicam com um outro seminário chamado Etnografia \& Educação em que trabalhamos mais detidamente as questões metodológicas e desenvolvemos uma experiência de pesquisa que envolve observação e iniciação ao trabalho de campo. 
3 PARTE IMPORTANTE DESSE ENCONTRO SE DEU POR MEIO DE SUA PESQUISA “MAISON DU BRÉSIL: UM TERRITÓRIO BRASILEIRO EM PARIS", PUBLICADA EM 20I4, E EM 2017 VOCÊ TAMBÉM PUBLICOU A COLETÂNEA JUNTO COM CARLOS VIANNA “A CASA DO BRASIL DE LISBOA: UM PROJETO VITORIOSO". PODERIA NOS FALAR SOBRE ESSES PROJETOS?

Conheci a Maison du Brésil durante o doutorado sanduíche. Morei na casa entre 2003 e 2004, num momento em que pesquisava sobre a construção das identidades regionais no sul do Brasil. A Maison du Brésil, inaugurada em 1959, como parte do projeto modernista do governo JK se situa na CIUP Cidade Universitária de Paris que está repleta de exibições identitárias que estabelecem um diálogo entre o cenário universitário francês e os estudantes que lá vivem temporariamente. A CIUP está situada em um parque de 40 hectares com residências de diversas partes do mundo. Ela foi construída no entre guerras, como parte do projeto pacifista e internacionalista do governo francês que objetivava também melhorar as condições de moradia dos estudantes que viviam no Quartier-Latin. O projeto CIUP teve e continua tendo dimensões educacionais que desafiam a interpretação de historiadores e cientistas socais da educação e que podem ser sistematizadas no slogan do seu idealizador André Honorat "Rapprocher les élites au service de la paix". Vir estudar em Paris e viver na Maison du Brésil dentro da CIUP, durante a pesquisa de doutorado, foi uma experiência educacional de amplo espectro que me levou a um projeto de pesquisa posterior, calcado na realização da Antropologia da Casa, em que tento trabalhar com o potencial educativo do habitar como ponto central da minha interpretação, mas há muitos elementos a serem destacados nesse percurso que extrapolam a resposta sucinta que devo elaborar para a questão proposta. Entendi, inicialmente, que estudar os processos de construção de identidade regional e suas territorializações não se afasta de outros processos identitários. Na Maison du Brésil, vi pessoas chegarem através do seu hall envidraçado projetado pela arquitetura modernista de Lúcio Costa e Le Corbusier, com expectativas de uma formação internacional na França, em uma casa brasileira, em que se recria quotidianamente o Brasil e suas regiões no exterior. Fiquei muito interessada em estudar esse espaço de desterritorialização/reterritorialização de identidades em que grupos e pessoas vivem temporariamente, desde que pisei na casa pela primeira vez. A Maison du Brésil de Paris foi para além de um cenário habitacional e de interlocução, onde os pesquisadores brasileiros em estágio na França e também estudantes estrangeiros (30\% dos habitantes da casa, a cada ano letivo vêm de outros lugares do mundo), vivi uma experiência plena de aprendizado de ser brasileiro em Paris. Lá o aprendizado do francês se mescla aos sotaques de várias regiões do Brasil e do mundo, em que se moldam simbólica e materialmente 
hábitos alimentares, novas noções de família e se aprende a viver coletivamente ao sabor dos limites construídos entre os espaços públicos e privados em que se divide a casa. Dada às discussões que desenvolvia para a tese, a Maison du Brésil foi um laboratório muito importante porque me mostrou na prática um emaranhado de identidades em construção, gestado ao sabor das subjetividades de pessoas e grupos, de gestores brasileiros e trabalhadores da casa, passando da vivência das regiões brasileiras e da imaginação e reprodução de imagens do que é o Brasil no exterior em um cenário internacional, à vida dos imigrantes e turistas brasileiros em Paris. Ela é uma casa nação, um território brasileiro.

Meu projeto de realizar uma antropologia da casa teve de aguardar até 2010 quando voltei à Maison du Brésil com um projeto de pós-doutorado financiado pela CAPES e o apoio de Anne Marie Thiesse da École Normale Superieur, com quem desde a realização do doutorado sanduíche já vinha dialogando sobre a construção de identidades regionais e nacionais. Novamente fui viver na Maison du Brésil para desenvolver um trabalho de campo de 12 meses sobre os significados de habitar a casa, sua história e questões educacionais que igualmente me levaram a outras Casas do Brasil na Europa. Primeiramente, a Casa do Brasil de Madri, também relacionada às exibições modernistas no exterior projetadas por JK e inaugurada em 1962, dentro da Ciudad Universitaria de la Complutense de Madri. Em 2014 tive o prazer de apresentar o livro Maison du Brésil: um território brasileiro em Paris na cafeteria da Maison du Brésil. Foi meu presente de aniversário para a casa que comemorava 55 anos. Foi uma experiência emocionante e de muito diálogo com seus habitantes e trabalhadores em um momento de profundas dificuldades para a Maison du Brésil.

Segui o fluxo das casas e minha questão de pesquisa do universo estudantil me conduziu ao mundo imigrante e às Casas do Brasil de Lisboa e Munique. Um trabalho que desenvolvi entre 2016 e 2017 e cujas imagens foram captadas pelo fotógrafo Alain Demarcy. Como resultado parcial da pesquisa que continuo desenvolvendo, há o livro que citaste e que se deu a partir do diálogo com Cristiana Bastos na Universidade de Lisboa que me recebeu como pesquisadora visitante. $\bigcirc$ livro organizado com Carlos Vianna é um trabalho pelo qual tenho um carinho muito especial porque se inspira na Antropologia da ação. Ele objetiva registrar a memória da atuação da Casa do Brasil de Lisboa ao longo de seus 25 anos de funcionamento e foi escrito com a participação de pessoas que atuaram e/ou ainda trabalham na casa. Outro trabalho relacionado à pesquisa que tenho desenvolvido em parceria com Alain Demarcy é a exposição itinerante "As Casas do Brasil na Europa". Ela foi apresentada em janeiro e fevereiro de 20।8 em 3 das 4 Casas do Brasil que pesquisamos, bem como está sendo levada a diversos eventos da Antropologia e Ciências Sociais. Para além de um retorno da pesquisa a nossos interlocutores, a exposição é uma forma importante de divulgar o trabalho que as Casas do Brasil efetuam na Europa. Do saldo desta experiência com as Casas do Brasil na Europa, ainda em curso, é imprescindível destacar que as etnografias mostram um universo plural de encontro de brasileiros no exterior que extrapola a vida estudantil e a 
sociabilidade muitas vezes revestida de saudades da comida e da música brasileira. As casas efetuam uma intermediação entre o universo europeu e a vida de seus frequentadores; são casas nação, territórios da brasilidade. Esse processo, em alguns casos, como em Lisboa (apesar de se falar português), adquire dimensões jurídicas e profissionais importantes na situação de regularização da documentação de imigrantes, de busca de inserção profissional e apoio psicológico, por exemplo. Meu encontro com cada uma dessas casas foi uma atualização do que acredito como uma das tarefas da Antropologia da Educação: a recuperação da sensibilidade para perceber as dimensões educativas dos processos culturais. Para ser imigrante, ser estudante, ser brasileiro no exterior é preciso aprender. As Casas do Brasil na Europa são espaços privilegiados em que se realizam esses aprendizados.

\section{OUTRA EXPERIÊNCIA RELEVANTE QUE VOCÊ EMPREENDEU FOI A COORDENAÇÃo DO PROGRAMA DE EDUCAÇÃo TUTORIAL (PET) INDÍGENA. QUAIS QUESTÕES MAIS RELEVANTES VOCÊ DESTACARIA EM TERMOS DE ENSINO E APRENDIZAGEM DESTA VIVÊNCIA?}

O PET Ñande Reko que significa nosso modo de ser, em guarani, foi criado na UFSM através do Programa Conexões e Saberes (um edital específico para fomentar experiências de pesquisas baseadas na circulação de saberes entre a universidade e as comunidades). Do ponto de vista institucional, o PET visava fomentar a participação de estudantes indígenas de diversos cursos de graduação, não apenas nas atividades de pesquisa e extensão, mas também incentivar seu protagonismo político para representação junto a instâncias institucionais (negociando e divulgando junto às terras indígenas o formato de seleção para ingresso na UFSM, por exemplo). Estive à frente do Pet como tutora entre os anos de 20 I I e 20 I 5. Foi uma experiência muito rica de conhecimento dos estudantes indígenas da UFSM, de suas demandas regionais e nacionais através das redes que formamos com outros grupos Pet indígena e estudantes de outras IES. Minha experiência como antropóloga da educação foi importante porque me conferiu a clareza de estar trabalhando com educação indígena e seus impasses, em que as vozes dos estudantes em prol das comunidades originárias deveriam falar mais alto. Apesar do nome do grupo remeter aos Guaranis, o grupo PET esteve aberto a outras etnias com a presença dos Kaingang e dos Terena. Partimos do conhecimento de cada um de nossos quatro estudantes em 20l I, de suas histórias de vida e, através do nosso diálogo, descobrimos pontos comuns. O mais relevante e perverso era a invisibilidade que vinham enfrentando dentro e fora da universidade. As pessoas simplesmente não acreditavam que eram índios reais porque estavam vestidos e porque se expressavam em português. Os caminhos para a compreensão dessa invisibilidade, para nossa atuação como grupo e tentativa de reversão desse cenário, me reportou a 
imaginários produzidos pela imagem do índio folclórico e literário que vivi em experiências de pesquisas anteriores. São muito populares no Brasil as representações de índios romantizados, com atributos brancos que se afastam dos indígenas atuais, em sua dinâmica cultural. A Iracema dos lábios de mel de José de Alencar e a figura de Sepé Tiaraju, festejada nos poemas O Uraguai de Basílio da Gama e no O Lunar de Sepé de João Simões Lopes Neto, deixou raízes fortes no imaginário popular. Ela alcança inclusive os manuais didáticos com os quais os professores trabalham no ensino fundamental, mesmo após a promulgação da lei | I.645/2008 que institui a obrigatoriedade da temática da "História e cultura afrobrasileira e indígena" nos currículos escolares. Nosso trabalho no Pet Ñande Reko, a partir das temáticas de pesquisa e de extensão escolhida por cada um de seus integrantes, (ligada com seu curso na universidade) foi de realizar um trabalho educacional com a comunidade de Santa Maria e região. Nas escolas de ensino fundamental, através de oficinas que levaram a língua e aspectos da cultura das etnias envolvidas, através da atuação dos estudantes petianos e das Ciências Sociais. No âmbito da universidade, realizamos vários encontros sobre educação indígena que alcançaram grande sucesso de público e o seu reconhecimento como alteridade. Nas comunidades Guarani e Kaingang do município foram implementados, em razão da demanda destes grupos, através da atuação dos estudantes do Pet, uma horta e um pomar, além de projetos de educação sanitária. Nosso trabalho foi uma tentativa de reverter estereótipos muito enraizados, através do incentivo da autonomia indígena. Demos alguns passos em direção a esse protagonismo, mas ainda há muito a ser feito. Acredito que a reversão dessa invisibilidade deve partir dos próprios indígenas, no recontar de suas histórias para consecução de suas reivindicações por terra, educação, saúde e respeito às suas dinâmicas culturais.

Vale a pena lembrarmos de Sepé Tiaraju, líder da resistência guarani, a quem se atribui a célebre frase "Esta terra tem dono" proferida por ele pós Tratado de Madri em 1750, por ocasião da troca acordada entre Portugal e Espanha, da Colônia do Sacramento pelos Sete Povos das Missões. A frase que levou à resistência guarani, entre 1754- |756, e a sua morte em uma rebelião colonial conhecida como Guerra Guaranítica, que dizimou cerca de 1600 guaranis, na Batalha de Caiboaté é sinônimo do desejo dos índios guaranis de permanecerem em suas terras. No entanto, a frase que vem sendo apropriada por diversos grupos no sul do Brasil, com Sepé sendo exaltado na literatura e folclore e encenado em teatro histórico ressalta suas virtudes de guerreiro branco. Assim, o mito que engendrou exclui os índios reais. Assim são percebidos os pobres e silenciosos guaranis que vendem seu artesanato na região das Missões. Em um movimento revolucionário da interpretação de Sepé, de seu significado histórico e mítico, guaranis e kaingangs, nos últimos 10 anos, têm atualizado o significado político da luta de Sepé pela terra das quais vêm sendo historicamente expropriados. Acredito nesse protagonismo e na importância de programas como o PET em revelar as escolhas das comunidades originárias, de facilitar a interlocução entre os estudantes e lideranças indígenas e de implementar suas demandas. A universidade tem um papel 
importante nesse diálogo, na construção de um mundo que conviva com as diferenças e abra as portas dos templos do conhecimento científico branco para as epistemologias nativas em seus modos de ser. Temos muito a aprender com elas.

\section{VOLTANDO-NOS PARA O CAMPO DO ENSINO DAS CIÊNCIAS SOCIAIS, EM 2008, COM A REINTRODUÇÃO DESTAS CIÊNCIAS NOS CURRÍCULOS ESCOLARES HOUVE O ADVENTO DE VÁRIAS LICENCIATURAS EM CIÊNCIAS SOCIAIS, INCLUINDO-SE Aí A DA UNIVERSIDADE FEDERAL DE SANTA MARIA. QUAIS OS DESAFIOS ENCONTRADOS PARA A CRIAÇÃO DESSE CURSO DE FORMAÇÃO DE PROFESSORES EM SUA INSTITUIÇÃO?}

Na UFSM a Lei $n^{\circ}$ I I.684, de 2 de junho de 2008 nos possibilitou, via edital REUNI, criar os cursos de licenciatura em Sociologia na modalidade EAD e na modalidade presencial, que posteriormente, após avaliação do MEC, recebeu um indicativo de adaptações e passou a se chamar Licenciatura em Ciências Sociais. Antes desse processo, efetuamos uma experiência de oferta de formação pedagógica complementar para egressos do Bacharelado em Ciências em 2007, para poderem atuar como professores de Sociologia. Foi essa experiência que nos mostrou a necessidade da criação dos cursos e de ultrapassar radicalmente o modelo $3+1$ que todos criticávamos. Queríamos fazê-lo com o desenvolvimento de um percurso ímpar. Sonhávamos criar um curso de Licenciatura em que todos os professores estivessem lotados no Departamento de Ciências Sociais, com o intuito de forjar uma identificação mais efetiva com ensino, pesquisa e extensão voltada para a formação de professores de Ciências Sociais e suprir o despreparo de boa parte do nosso corpo docente para lidar com as licenciaturas nascentes. Essa foi nossa maior dificuldade. A burocracia universitária não permitiu a concretização dessa configuração. Assim, parte de nossos professores ficou vinculada a diversos departamentos didáticos o que não nos garantiu o compromisso e/ou investimento na formação de professores de Ciências Sociais. Por outro lado, essa burocratização da interdisciplinaridade nos impulsionou a criar mecanismos que garantissem uma discussão mais específica a respeito da formação de professores de Ciências Sociais e foi por essa razão que as disciplinas de Sociologia da Educação e de Antropologia da Educação ficaram lotadas no Departamento de Ciências Sociais. Com o andar dos cursos, começamos a criar Disciplinas Complementares de Graduação que também passaram a dialogar com a formação de professores de Ciências Sociais e com a produção de materiais didáticos. Foi assim que foram introduzidos o seminário de Ciências Sociais para o Ensino Médio e os Trabalhos de Conclusão de Curso, na Licenciatura em 
Ciências Sociais da UFSM, que depois se tornaram obrigatórios. Na verdade, creio que estamos conseguindo dialogar com esses desafios iniciais encontrados no curso de graduação, mas é preciso ressaltar a luta diária contra a evasão nos cursos noturnos, em tempos da Reforma de Ensino médio e o desmonte que o governo vem procedendo a cada nova medida na educação pública no país, em todos os níveis. A busca de soluções tem sido desesperadora para todos nós e a distância entre docentes e discentes vem-se estreitando, o que considero positivo. Estamos no mesmo barco e não queremos que ele afunde, por conta de uma medida provisória impopular. Dez anos se passaram da promulgação da lei | I.684 e nosso cenário é animado por uma Base Nacional Comum Curricular e a lei 13.415, de I6 de fevereiro de 2017 que institui novo o ensino médio. Tenho a impressão de que estamos diante de enormes desafios e desejo que sejamos capazes de superá-los.

\section{VOCÊ TAMBÉM COORDENOU UMA PESQUISA SOBRE COMO OS CIENTISTAS SOCIAIS SE TORNAM PROFESSORES. PODERIA NOS FALAR UM POUCO SOBRE COMO ESSE PROCESSO OCORRE?}

A pesquisa surgiu do diálogo com a turma especial (aquela primeira que já referi) de 2007 antes mesmo da obrigatoriedade legal da Sociologia no ensino médio. Estranhamos a inexistência de um programa para ser utilizado pelas escolas de ensino médio. Na época, entendíamos que as Orientações Curriculares Nacionais (OCNs) não eram suficientemente claras e acessíveis para inspirar a prática pedagógica de professores sem formação em Ciências Sociais, o que era a realidade da maior parte das escolas no Rio Grande do Sul. A pesquisa, além disso, queria fazer um mapeamento das condições de formação e trabalho de quem estava atuando e propor uma parceria entre a universidade e a secretaria estadual de educação, para preparar a chegada da Sociologia nas escolas de ensino médio, conforme anunciava a lei. Trabalhamos vários anos com essa perspectiva, fizemos um mapeamento e começamos a esboçar um programa e referências bibliográficas. Com a entrada da Sociologia no Vestibular da UFSM fomos convidados para selecionar os conteúdos programáticos. Por entendermos que a Sociologia no ensino médio abrangia as três áreas das Ciências Sociais, construímos um grupo de discussão formado por antropólogos, sociólogos e cientistas políticos que deu origem à seleção de tópicos tematizados no vestibular e começamos a nos interessar pela elaboração de um material didático, mas não conseguimos desenvolvê-lo. O projeto continuou o seu curso financiado pelo edital PROLICEN e foi interrompido com a adesão da UFSM ao SISU/ENEM. Este projeto serviu de inspiração para a elaboração da disciplina Ciências Socais para o ensino médio. 


\section{DENTRO DO CURRÍCULO DA LICENCIATURA EM CIÊNCIAS}

SOCIAIS DA UFSM FOI INTRODUZIDA UMA DISCIPLINA SOBRE ENSINO

DAS CIÊNCIAS SOCIAIS, QUE VOCÊ LECIONOU ALGUMAS VEZES, QUAIS TEMAS SÃO DEBATIDOS? COMO PENSAR UMA ABORDAGEM ANTROPOLÓGICA PARA O ENSINO DA SOCIOLOGIA NO ENSINO MÉDIO?

A disciplina se chama Ciências Sociais para o ensino médio e incorporou um conjunto de inquietações que surgiram no projeto. Como os sociólogos se tornam professores? O principal objetivo, desde a sua criação, foi propiciar aos estudantes de Licenciatura em Ciências Sociais uma experiência de autoria de um capítulo voltado para o ensino de Sociologia no ensino médio, a partir da escolha de temas de qualquer uma das três áreas das Ciências Sociais. Até chegarmos a esse momento de escrita e de suas apresentações e amadurecimento do texto, através de debates em sala de aula, trilhamos um caminho que defino como de contato como o ensino de sociologia na escola brasileira. Iniciamos com uma breve abordagem histórica e legislativa até chegarmos à lei I I.684/2008 e dialogamos com algumas experiências de ensino/aprendizagem em Sociologia publicadas em revistas da área nos últimos 10 anos. A incorporação de uma abordagem antropológica da sociologia no ensino médio não se resolve apenas pela inclusão de conteúdos mais caros à Antropologia. É preciso criar um entendimento entre nossos futuros professores de Sociologia de que eles irão trabalhar em uma perspectiva abrangente das Ciências Sociais no ensino médio. Isso passa também pelas reflexões que a Antropologia pode propor sobre os processos de ensino/aprendizagem e sobre as transformações impostas pelo cenário brasileiro contemporâneo que tende a desconstruir, via BNCC, a importância da Sociologia e da Filosofia no ensino médio, no meu entendimento. Na versão atual da disciplina, que estou trabalhando neste momento, abrimos um espaço privilegiado para discutir a reforma do ensino médio proposta na lei 13.4 I5/2017, a Base Nacional Comum Curricular e a Escola sem Partido. Num segundo momento, passaremos ao debate sobre conhecimento, aprendizagem e linguagem das ciências sociais no ensino médio que se relacionam ao debate sobre transposição didática e (re)contextualização dos conteúdos científicos e a análise da cultura escolar. Entendo que uma discussão sobre os sentidos da escola para a juventude que passa por etnografias recentes das práticas escolares, tais como as ocupações secundaristas e as percepções dos lugares do ensino médio na vida dos estudantes, é fundamental de ser pensada por futuros professores. Por fim, acredito que a escrita deve ser parte integrante da vida do professor e de sua preparação. Nos cursos de formação de professores creio que esse aspecto vem sendo bastante negligenciado. Vivenciar a produção de material 
didático através da escrita é a nossa proposta de desenvolvimento da prática como componente curricular na disciplina de Ciências Sociais para o ensino médio, na UFSM.

\section{MAIS RECENTEMENTE, VOCÊ FICOU À FRENTE DO COMITÊ DE EDUCAÇÃO, CIÊNCIA E TECNOLOGIA DA ASSOCIAÇÃO BRASILEIRA DE ANTROPOLOGIA (ABA). PODERIA NOS FALAR SOBRE AS ATIVIDADES DESENVOLVIDAS POR ESTE COMITÊ?}

O comitê tem uma proposta de pensar como antropólogas e antropólogos as características da EC\&T no Brasil e as transformações que nos afetam, assessorando a diretoria da ABA, quando solicitados. Somos cinco docentes de diferentes cantos do Brasil com atuação em educação e ciência nas universidades onde trabalhamos. Tenho aprendido muito com essa experiência e sou grata à Associação Brasileira de Antropologia pelo convite para participar da comissão. Acho que é consenso que os dois últimos anos foram brutais e desesperadores. Perdemos em financiamento, autonomia e produção de conhecimento, além do desrespeito às comunidades tradicionais, perdas na educação das quais a reforma do ensino médio é apenas um dos exemplos. As universidades vêm sendo sacudidas pelas comissões de heteroidentificação que minam as cotas raciais e sociais. Conquistas recentes que mudaram o cenário do país vêm sendo cortadas sem maiores explicações que a falta de recursos. A presença de atitudes homofóbicas nas escolas, o movimento escola sem partido, o racismo expresso e a violência aos mais vulneráveis desenham um cenário de conservadorismo e de clara exclusão, de uma mentalidade retrógrada e eugênica. Temos tentado resistir a tudo isto, nos associando a outros comitês de entidades e nos manifestando junto ao MEC e outras instâncias, inclusive jurídicas. Nossos fóruns propositivos têm sido os encontros de Antropologia onde estamos debatendo, através de mesas redondas e simpósios, grande parte dos temas citados e pretendemos também difundir os resultados através de publicações. Sabemos que não é suficiente, mas é o que conseguimos fazer até o momento. Este é um momento de dor e tristeza para todos os antropólogos brasileiros e do mundo. Foram as chamas do descaso, do descompromisso com a educação, com a ciência e com o patrimônio nacional que consumiram o Museu Nacional no Rio de Janeiro e destruíram nosso maior e mais antigo acervo em diferentes áreas. Nesse momento, as ruínas do museu nacional têm um papel pedagógico importantíssimo que vai muito além de evitar seu esquecimento. Produzir o entendimento de que há perdas irreversíveis e irrecuperáveis. De que existem prioridades. A educação é uma delas. 


\section{POR FIM, EM SUA PERCEPÇÃO QUAIS SERIAM OS DESAFIOS PARA O ENSINO DE ANTROPOLOGIA NO BRASIL HOJE E QUAL O PAPEL DESSA CIÊNCIA NA ESCOLA? CONSIDERANDO O CONTEXTO QUE TEMOS VIVENCIADO MARCADO PELA EMERGÊNCIA DE MOVIMENTOS COMO “ESCOLA SEM PARTIDO”.}

Estamos vivendo dias complicados no Brasil, anos - nada dourados - marcados por uma pobreza que é no meu entendimento intelectual, para além de econômica e de crise mundial. Diante dos nossos olhos, a escola pública vem-se desmantelando. A primeira coisa a sublinhar é o desrespeito aos colegas professores com seus salários miseráveis sendo parcelados. Parece que há um desejo não dito de solapar a dignidade das pessoas e de obrigá-las a abdicar de seu potencial crítico e criativo. A escola sem partido para mim é isso: o primeiro passo de uma imposição ideológica que se representa como neutra e antiideológica. Queria acreditar que deixamos para traz na história da epistemologia os discursos da neutralidade, mas talvez esse fantasma positivista ainda viva em algumas universidades e centros de pesquisa do mundo. Nas escolas, ele não é um espectro. Está sendo gestado como algo real do qual talvez o próximo passo seja a imposição da doutrina criacionista. Em nenhum momento da história do Brasil necessitamos tanto de antropologia, para aprendermos a estranhar tais proposições e a refutá-las através de um exercício coletivo de relativização que possa nos conduzir ao respeito às diferenças e à proteção das vulnerabilidades em todos os níveis. Com o andar dessa carruagem, o mais urgente talvez seja a recuperação dos sentidos de aprender e ensinar o que as ocupações secundaristas reclamavam. Em tempos de esgotamento, talvez nosso maior desafio seja extrapolar a escola e procurar aprender com sujeitos que construíram para transmissão cultural outros espaços educativos para além da escolarização. Precisamos aprender com os universos tradicionais que a Antropologia tem ao longo de sua história estudado, para ensinar o respeito à diferença, para reconstruir nossos cenários culturais de escolarização. 